\title{
Medical miracle claimed for Canadian explorer
}

Previously published at www.cmaj.ca

I $\mathrm{n}$ his long and remarkable life (1770-1857), David Thompson worked for the Hudson's Bay Co. and the Northwest Co., traded with Indians from Hudson Bay to the Pacific and spoke both Cree and Blackfoot. He learned the science of practical astronomy, which allowed him to calculate coordinates of latitude and longitude, as he explored regions then known only to the Indians. Later, he used these observations to create a map of lands now known as Western Canada. Thompson, who had seven years of formal schooling, achieved all this despite a disability: In February 1789, while mastering practical astronomy, he lost the sight in his right eye.

In 1812, Thompson left the west and settled near Montréal, Quebec, where he led the team of British surveyors that worked with American counterparts after the War of 1812 to draw a border between present-day * Cornwall, Ontario and Lake-of-theWoods. He went bankrupt in 1836, at age 66, and he and his Métis wife, Charlotte Small, endured an impoverished old age in and around Montréal. He contracted cholera in the early 1840 s and survived, but then, toward

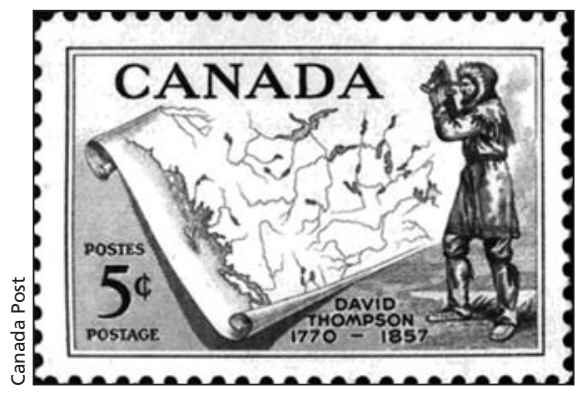

This 1957 Canadian stamp, designed by George Arthur Gundersen and engraved by Yves Baril, celebrates Thompson's success as an explorer. He is depicted holding a sextant.

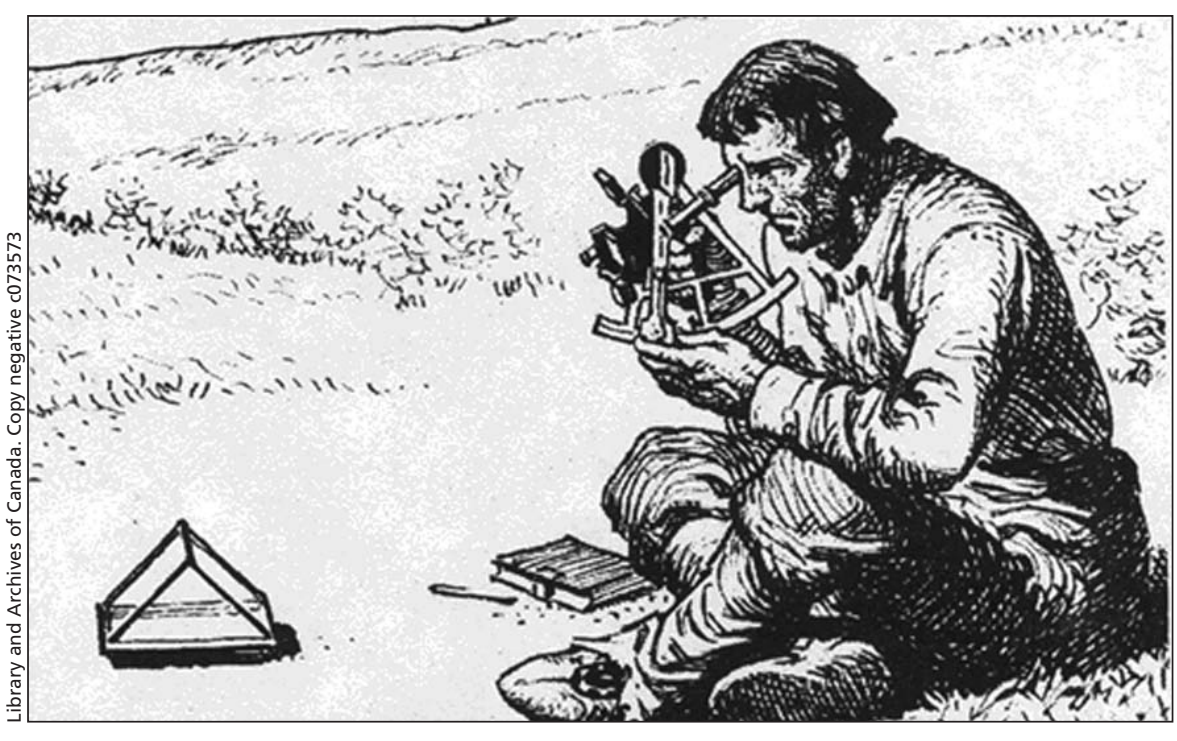

Despite having sight in only one eye, Thompson became renowned for his skills as a cartographer. This sketch by CW Jefferys (1869-1951) is entitled: "David Thompson taking an observation."

the end of 1847, the vision in his good left eye became blurred. One morning in February 1848 he awoke completely blind.

Fortunately, a son-in-law paid for medical expenses. Montréal physician, Henry Howard, treated Thompson and his summary of the case later appeared in the book, The Anatomy, Physiology and Pathology of the Eye. "I examined his eyes," Howard wrote, "and found he had capsulo-lenticular cataract of the left eye, fully ripe for operation; and a cicatrix in the centre of the right cornea, so surrounded by lymph as to render the whole of the cornea opaque, causing it to appear as though the sclerotic extended over the front of the eye; not one portion of the iris was observable through it."

Howard treated Thompson daily in the following manner: "His eyes were fumigated with hydrocyanic acid and his eyebrows, lids and temples brushed with the solution of veratria; sparks of electricity were drawn from round the orbit about three times a week and occasionally I dropped on the conjunctiva the two grain solution of atropine. For the first two weeks, he took every morning a wine glass full of the infusion of gentian, containing a small quantity of the sulphate of magnesia, and sulphuric acid."

After three weeks of treatment, Thompson had regained his vision to the point where he could walk unassisted to Howard's office. After three months, he was able to read and write. One day he told the physician that: "On the previous evening he had seen a particular star with his right eye for the first time since he was of the age of 19." On examination, the cataract had disappeared, the corneal edema had cleared and the iris could be visualized

This curious case recently came to the attention of Dr. John Speakman, a former staff ophthalmologist at Sunnybrook Hospital in Toronto, Ontario. Speakman concluded that the physician's description of the problems with 
Thompson's eyes was precise and accurate though he describes the treatment as "quite unbelievable" and of no benefit.

Thompson had two distinct problems, says Speakman, and each resolved itself spontaneously, as unusual as that may be. Thompson likely suffered an injury to his right eye, which caused a cataract to form. (He suggests a musket may have exploded upon discharge, or a sliver of metal or stone may have become embedded in the eye.) This cataract was hypermature by the time Thompson was an old man and Speakman speculates that either the fluid in the lens capsule leaked, or possibly the cataract dislocated posteriorly into the vitreous, leav- ing the visual axis clear and eye capable of resolving images.

As for the left eye, Speakman believes that Thompson may have suffered from acute corneal hydrops. When this happens, the corneal stroma becomes distended and opaque as a result of fluid leaking through a tear in the corneal endothelium from the anterior chamber. However, the endothelium is capable of regenerating spontaneously and this usually takes place over a period of two to three months. As the fluid is absorbed, the cornea regains it transparency. "I've only seen it two or three times," says Speakman. "It happens quite quickly and it's frightening for the patient."

The ophthalmologist concludes that it was a coincidence - and a highly unusual one - that two distinct problems should resolve themselves almost simultaneously. "David Thompson must have thought a miracle had occurred," says Speakman.

\section{D’Arcy Jenish BA}

Journalist

Ajax, Ont.

D'Arcy Jenish is the author of Epic Wanderer: David Thompson and the Mapping of the Canadian West (Doubleday; 2003).

\section{REFERENCE}

1. Howard H. The Anatomy, physiology and pathology of the eye. Montreal (QC): Armour and Ramsay; 1850 . p. 357-8. 